This is an author produced version of a paper published in Livestock Science.

This paper has been peer-reviewed but may not include the final publisher proof-corrections or pagination.

Citation for the published paper:

Anne-Charlotte Olsson, Jørgen Svendsen, Jos Botermans, Christer Bergsten. (2016) An experimental model for studying claw lesions in growing female pigs. Livestock Science. Volume: 184, pp 58-63.

http://dx.doi.org/10.1016/j.livsci.2015.12.005.

Access to the published version may require journal subscription.

Published with permission from: Elsevier.

Standard set statement from the publisher:

(C) Elsevier, 2016 This manuscript version is made available under the CC-BY-NC-ND 4.0 license http://creativecommons.org/licenses/by-nc-nd/4.0/

Epsilon Open Archive http://epsilon.slu.se 


\title{
AN EXPERIMENTAL MODEL FOR STUDYING CLAW LESIONS IN GROWING \\ FEMALE PIGS
}

Anne-Charlotte Olsson ${ }^{\text {a }}$, Jørgen Svendsen, Jos Botermans and Christer Bergsten

Swedish University of Agricultural Sciences, Department of Biosystems and Technology, P.O. Box 103, SE-230 53 Alnarp, Sweden

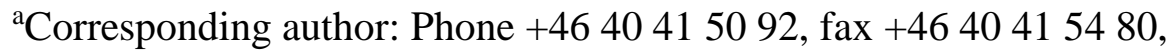
mail<anne-charlotte.olsson@slu.se>

Keywords: Sows; claw lesions; regrouping; aggression; flooring

\begin{abstract}
Problems with claw lesions leading to lameness are a growing concern in pig production. However, the causes and development of claw lesions are poorly understood and studies on prevention of claw lesion problems in gilts and sows are limited.

This study tested a new experimental model which facilitates evaluation of the impact of different risk factors on pig feet lesions.

The model consisted of using young gilts with a well-known background and promoting traumatic claw lesions for study purposes by increasing social and agonistic activity through regrouping on concrete flooring. Then claw lesions were assessed systematically and objectively on feet after slaughter. To test the model, two levels of exposure to concrete flooring were compared; normal activity in groups of gilts (no regrouping $=\mathrm{NR}$ ) and increased activity in groups of gilts by performing several regroupings (repeated regrouping $=$ $\mathrm{RR})$.
\end{abstract}

A total of 72 gilts (pairs of litter mates) in two batches, aged 4 months, were randomly distributed to the two treatments (NR and RR) in group pens (3 gilts per pen) with concrete 
flooring. The gilts were given approximately $200 \mathrm{~g}$ of straw per gilt every day. At 8,9 and 10 months of age, half the gilts (36 animals) were regrouped with each other. At 11 months of age, all gilts in both treatments were slaughtered and the left rear foot from each was removed and collected for detailed studies of claw lesions. Lesions of the heel, transition heel/toe, white line, wall and toe and over-growth of the heel were assessed on the outer and inner digit. Blind scoring of claw lesions on a scale from 0 to 3 was carried out in laboratory conditions on cleaned claws. Body lesions were also blind-scored on a scale from 0 to 3 one week after the third regrouping.

The results showed claw lesions on the soft and hard horn of the claws and significantly ( $p=0.004)$ higher claw lesion score in RR gilts (0.40) than in NR gilts $(0.23)$.

It was concluded that as expected, regrouping gilts on concrete flooring resulted in both more numerous and more severe claw lesions than ungrouped gilts. Likewise, body lesion score was significantly $(\mathrm{p}<0.001)$ higher in RR gilts $(1.71)$ than NR gilts $(0.46)$.

It was also concluded that the proposed model could be a successful experimental design for challenging different risk factors, e.g. flooring and management, for development of claw lesions in pigs.

\section{Introduction}

Lameness in sows is very common and a serious concern in pig production (Pluym et al., 2011). A lame sow is in pain, has reduced appetite, loses weight and has problems showing oestrus and conceiving (Willgert et al., 2014; Wolf, 2011). In addition to poor animal welfare and considerable suffering, the pain behind lameness causes economic losses due to reduced performance, involuntary culling and reduced longevity (Anil et al., 2009; Engblom et al., 2008; Jensen et al., 2010). 
One of the reasons for lameness is poor claw health, e.g. through injuries of the claw capsule including sole, wall, white line and heel or bulb (Cador et al., 2014; Enokida et al., 2011; Mustonen et al., 2011). The causes of claw lesions are complex and multifactorial, including genetics (e.g. small inner claws and abnormal toe angles), nutrition (e.g. lack of biotin), management and environment (e.g. flooring) (Vestergaard et al., 2005). Claw lesions have been reported in young pigs (Kilbride et al., 2009b), but the prevalence appears to increase with the age of the animal and during gestation, while a temporary decrease during the lactation period has been reported (Anil et al., 2007; Pluym et al., 2011). Various sow herd survey studies have reported an incidence of claw lesions of 60-90\% (KilBride et al., 2010; Olsson and Svendsen, 2002; Pluym et al., 2011).

The floors in modern pig pens often consist of concrete, which is harsh and abrasive for sensitive feet and legs. Lack of litter as bedding increases the risk of contusions and leg injuries in both sows and piglets (Ehlorsson et al., 2002; Jorgensen, 2003; Olsson and Svendsen, 2004). Slatted concrete is better for hygiene than solid concrete (Gjein and Larssen, 1995a; Jorgensen, 2003; Olsson and Svendsen, 2004), as wet, manure-contaminated surfaces with excess ammonia have been shown to make the claws soft and more susceptible to damage and bacterial infections (Borderas et al., 2004; Vestergaard et al., 2005). However, concrete slats can have poor design and sharp edges (de Koning, 1984).

Problems with claw lesions are also reported to be more common in systems with concrete floors and group housing than in systems with concrete floors and individual housing in crates (Anil et al., 2007; Pluym et al., 2011; Svendsen et al., 1990). This can be interpreted as that animal activity/agonistic contacts among the animals (stable or dynamic groups of animals) implies an additional risk for the onset of claw lesions. Some authors have requested more research in this area to find measures to prevent such lesions (Anil et al., 2007; Pluym et al., 2011). A logical step in promoting healthy feet and improved sow longevity, at the present 
state of knowledge, is to find and test improved flooring systems in group housing facilities. According to our experience (Olsson \& Svendsen, 2002), scientific claw studies under the conditions found in practice are challenging. A golden standard experimental model to study claw lesions in pigs would be beneficial. For example, it can be questioned whether studies of claw lesions can be performed sufficiently accurate and detailed on live animals.

Since the causes to claw lesions are complex and multifactorial there is a need for a study method in which genetics, age, weight, reproductive stage, management etc. are equal and earlier claw lesions and treatments are minimized or absent. Furthermore, if pigs are studied in different group housing systems under non-standardised conditions it may be difficult to draw any conclusions.

Therefore, the aim of this study was to test a model for future claw lesion studies. The idea was to use young gilts, in order to guarantee a well-known healthy background, and to provoke claw lesions by regrouping these gilts in a common housing system with concrete flooring. A refined method for systematic and objective assessment of claw lesions in the feet of slaughtered pigs was then tested. The hypothesis was that increased animal activity on hard concrete floors is one possible explanation for the development of claw lesions in pigs. Thus, this treatment could be used as a control in a model for future claw lesion studies.

\section{Materials and methods}

\section{$\underline{\text { Housing and management }}$}

The experiment was carried out at Odarslöv Pig Research Farm, Swedish University of Agricultural Sciences (SLU), Alnarp, southern Sweden. The closed herd comprised 50 sows in an integrated growing-finishing pig production system. A rotation breeding programme (Yorkshire and Swedish Landrace) is used in the sow line. 
Each pen for gilts had a total area of $4.86 \mathrm{~m}^{2}(1.35 \mathrm{~m} \times 3.60 \mathrm{~m})$ divided into a solid concrete feeding and resting area of $3.04 \mathrm{~m}^{2}$ and a slatted dunging area of $1.82 \mathrm{~m}^{2}$ (concrete slats with $20 \mathrm{~mm}$ slot width and $80 \mathrm{~mm}$ slat width $)$. The feeding trough $(0.35 \mathrm{~m} \mathrm{x} 1.35 \mathrm{~m})$ was placed along the short side of the feeding and resting area, towards the feed alley (Fig. 1). Two water nipples were placed above the feed trough and another was placed in the dunging area. The gilts were fed a dry diet twice a day according to Swedish feeding recommendations for pigs (SLU, 2014). Straw (0.6 kg per pen) was provided as bedding, once a day after the first meal.

\section{$\underline{\text { Experimental design }}$}

A total of 72 gilts, in two batches, were selected for the study. Only animals, judged as healthy were used in the experiment. The gilts were assessed to be healthy by checking that they had a normal gait (no lameness), a normal growth and good appetite and were free from disease problems during rearing. All gilts (pairs of litter mates) had the same background with respect to housing/flooring and management during the early rearing period. At 4 months of age and a weight of $35-45 \mathrm{~kg}$, the litter mates were randomly distributed to one of two treatments (normal activity in groups of gilts (no regrouping $=$ NR) and increased activity in groups of gilts by performing several regroupings (repeated regrouping $=\mathrm{RR}$ )). Each batch of 36 gilts was split into six pens in the NR treatment and six pens in the RR treatment, i.e. three gilts per pen (Fig. 1). About three months later the gilts were inspected for leg problems and no obvious signs of lameness, leg or claw problems were found. At 8 months of age, gilts within treatment RR were regrouped with gilts in the other pens in the same treatment group (Table 1). The gilts were returned to their original groups a week later. This procedure was repeated at 9 and 10 months of age, according to a certain schedule (Table 1), which meant that the gilts met new individuals at each grouping. The gilts in treatment NR were kept in their original groups throughout the whole study period. 
At 11 months of age, all gilts were sent to slaughter. Before scalding, the left rear foot of each gilt was removed and collected. A rear foot was chosen because claw lesions are more prevalent and more severe on the rear legs than on the front legs (Kornegay et al., 1990) and a left foot was chosen since the slaughtered gilts were hung up by their right hind leg.

\section{$\underline{\text { Claw and body lesion recording }}$}

A blind examination of claw lesions on the left foot samples was carried out in the laboratory, by the same veterinarian in all cases. Lesions on the heel, transition heel/toe, white line, wall and toe and over-growth of the heel (excessive heel horn extending over the sole horn) were assessed on the outer and inner digit of the foot, according to Gjein and Larssen (1995c). However, instead of a five-point scoring system (1-5), we used a four-point system (0 to 3, where $0=$ no lesions/no overgrowth, $1=$ one or few superficial cracks or lesions/slight overgrowth, 2 = longer and deeper cracks and lesions/moderate overgrowth, $3=$ deep cracks and lesions extending into the corium, with signs of inflammation or bleeding/extensive overgrowth involving the whole heel). The maximum possible sum of claw lesion scores for an animal was 36 (six recordings per digit and two digits) and the maximum mean claw lesion score for an animal was 3 (sum of claw lesion score divided by 12). A mean claw lesion score was also calculated for each pen as an average value for all pigs in the pen. In addition, mean claw lesion score was divided into mean lesion score in the soft horn (heel, over-grown heel, transition heel/toe) and mean lesion score in the hard horn (wall, white line, toe).

The assessment of body lesions was made on all the gilts one week after their return to the original group after the third regrouping (see Table 1), as a blind test by an experienced veterinarian in a well-lighted area outside the gilt pens. Lesions were visually scored, using a scoring system employed in earlier studies at our department (Olsson et al., 2011), on four 
different body areas (head, body, legs and vulva) on a scale from 0 to 3 ( where $0=$ no lesions, 1 = few minor and superficial scratches, $2=$ several minor superficial scratches and/or larger superficial scratches, $3=$ wounds/bites penetrating the epidermis, with ulceration, bleeding or swelling. The maximum possible sum of body lesion scores (four positions) for an animal was 12 and the maximum mean lesion score for an animal was 3. A mean body lesion score was also calculated for each pen, as an average value for all pigs in the pen.

\section{$\underline{\text { Calculations and statistics }}$}

The observations of claw and body lesions were treated as a mean value per gilt and a mean value per pen. Descriptive statistics, frequency and scatter plots of claw and body lesions were performed per gilt using the Minitab 16 software (Minitab, 2011). The procedures Wilcoxon signed rank test (comparisons within the same animal (pairwise measurements)), chi-square (comparisons between NR and RR gilts (two independent samples)) and correlation (between average claw lesions score and average body lesion score) were used when analysing averages per gilt.

PROC GLM (General Linear Model) in SAS 9.2 (SAS, 2009) was used for statistical analysis of mean claw lesion score, mean claw lesion score in the soft horn, mean claw lesion score in the hard horn and mean body lesion score per pen. The averages per pen were used in these calculations, since pen was considered an independent unit of observations. The statistical model included the effect of treatment and batch. The interaction between treatment and batch was tested and found not to be significant. Before the PROC GLM test, the variables were tested for normal distribution and a normal distribution could not be rejected for the current variables.

\section{$\underline{\text { Ethical considerations }}$}


This study was conducted in accordance with a specific permit from The Swedish Board of Agriculture (Dnr 5.2.18-6420/13) on using pigs for the research.

\section{RESULTS}

Results of claw and body lesion scores for NR and RR gilts are presented in Table 2. Claw lesions score and soft and hard lesion scores were significantly higher in RR gilts than in NR gilts (Table 2).

The lesions were not equally distributed between the outer and inner digits, with most lesions appearing on the outer digits (Figs. 2 and 3). For soft horn lesions, the difference between outer and inner digits was more prominent (Wilcoxon sign rank test, $p<0.001$; Fig. 2) than for hard horn lesions (Wilcoxon sign rank test, $\mathrm{p}=0.034$; Fig. 3). Soft horn lesions on the inner digits were more prevalent in RR than in NR gilts (chi-square $=8.1 ; \mathrm{p}=0.004$ ), while the difference was not as pronounced between treatments for the outer digits (chi-square $=0.8$; $\mathrm{p}=0.35$; Fig. 2). Hard horn lesions were also more prevalent and more severe in RR than in NR gilts and the difference was greater for inner digits (chi-square $=5.8 ; \mathrm{p}=0.015$ ) than for outer digits (chi-square=2.7; p=0.099; Fig. 3)

The RR gilts had significantly higher body lesion score than the NR gilts (GLM, p<0.001; Table 2). The correlation coefficient between body lesion score and claw lesion score was 0.36 ( $\mathrm{p}=0.002$; Fig. 4) 
No significant differences in body lesion score, claw lesion score or soft horn lesion score were found between batches. However, there was a significant difference (GLM, p=0.027) between batches for hard horn lesion score, with the score being higher in batch $1(0.16)$ than in batch $2(0.10)$.

\section{DISCUSSION}

Substantial research efforts have already been devoted to work out methods for assessment and evaluation of lameness and claw lesions (Grégoire et al., 2013; Nalon et al., 2013; Pluym et al., 2013a). However, to improve longevity in sows and thereby make modern intensive pig production more sustainable, there is still a need for more studies on measures to prevent lameness and claw lesion problems. This in turn would require optimal tools for studying claw lesions and better knowledge about the conditions in which claw lesions become a problem and how to solve them under these conditions.

Much research interest is devoted to animal behaviour, animal activity and animal competition in different housing systems. The model proposed here may for example be used for evaluation of different management systems on claw disorders. As housing systems become more technologically advanced and group size increases, interactions between animals within a housing system become more complex and more difficult to monitor.

Previous screening and cross-sectional studies on different commercial farms have shown that claw lesion problems are a multifactorial complex, influenced by factors such as weight, age, feeding, genetics, earlier experience, flooring, housing and management routines (Anil et al., 2007; Díaz et al., 2014; Ehlorsson et al., 2002; Olsson and Svendsen, 2002; van Amstel and Doherty, 2010). Field studies such as these provide valuable information about the prevalence and severity of claw problems in practice, but due to large variations in many factors interpretation of the results is difficult. Therefore, the first key principle within our proposed 
model was to standardise these factors by working with young female pigs with similar genetic background within the same farm. When working with young, healthy and homogeneous animal stock within the same herd, causal factors such as those mentioned above are standardised.

However, since young healthy animal stock probably have few claw lesions at the start of the experimental study, a particular treatment known to cause claw lesions under common housing conditions is needed to create lesions for study purposes. Therefore, the second key principle in the proposed model was to apply a treatment believed to provoke claw lesions in pens with concrete flooring. The treatment used was repeated regrouping (RR) of the gilts with the intention of increasing social conflict and agonistic activity in the gilt groups. Grouping and regrouping is common practice in pig production (Bench et al., 2013; Greenwood et al., 2014; Stevens et al., 2015). To test and verify our hypothesis that increased social and agonistic activity in gilts generates more claw lesions, the RR treatment was compared with NR (no regrouping). The results showed that increased social and agonistic activity by regrouping, in pens with concrete floors and limited amounts of straw, caused both more numerous and more severe claw and body lesions.

Several studies have concluded that claw lesions are more frequent in group housing than in individual housing (Anil et al., 2007; Cador et al., 2014; Pluym et al., 2011). Since group housing of pregnant sows is now compulsory in the entire EU (EU, 2008), there is a need for better flooring types and management systems to avoid the risk of increasing claw problems in the future. In particular, group housing of sows on fully or partly slatted concrete floors without or with limited amounts of bedding is known to be linked to claw problems (Cador et al., 2014; Ehlorsson et al., 2002; Heinonen et al., 2013; Olsson and Svendsen, 2002; Pluym et al., 2013). The present study showed that increased animal social and agonistic activity in such housing systems exacerbates the problems. There was a significant difference in body 
lesion score at the end of the regrouping, confirming the expected increase in social and agonistic activity. The correlation between body lesion score and claw lesion score per gilt also indicated a relationship between involvement in aggressive activities and increased claw lesion score, although the correlation coefficient was low (0.36). Even though no formal behavioral studies of agonistic behavior were made in our study, the conclusion above is considered reasonable since other studies (Stukenborg et al., 2011) have shown that recording of lesions is an adequate method for analysing fighting behavior under commercial farm conditions.

We also found that claw lesions were more frequent and severe on both the inner digit and the outer digit when the gilts were exposed to several regroupings. Since weight distribution on the claws explains where claw lesions occur (Anil et al., 2007; Díaz et al., 2014; Nalon et al., 2013), this finding can be interpreted as more weight being put on both the outer and inner claw digits during agonistic behaviour. However, animal behaviours in relation to social conflicts are more complex than only a matter of weight distribution during aggression (Camerlink et al., 2014), so more detailed studies of individual behaviour at regrouping would probably have resulted in a better understanding of the increase in claw lesions in the different individuals. The extent, to which an individual animal was involved in an unexpected movement and aggression, where in the pen the aggression happened (on the slatted or the fully concrete floor), and whether a particular animal won or lost a fight and as a consequence of this may stay in a clean pen area or is forced to the dung area, are examples of such interesting details.

Our results suggest that there are differences between group housing systems, with disadvantages in systems with frequent regroupings and high levels of social and agonistic activity. This corresponds well with findings reported previously by Anil et al. (2009) and Cador et al. (2014). Cador et al. (2014) found more sows with leg problems in large groups 
and in electronic sow feeding (ESF) systems than in small groups with walk-in, lock-in stalls (WLS). Furthermore, within a particular housing system, the level of injuries to the animals is influenced by animal flow and group management (e.g. static or dynamic groups) (Li and Gonyou, 2013) and the technical settings of the feeding system (Olsson et al., 2011). Differences in the level of social and agonistic activity probably explain this. Pros and cons of different group housing systems for non-lactating sows and different strategies for the animal flow in the herd need to be explored further.

The third key principle in the proposed model was to provide conditions for more thorough, objective, blind and less laborious assessment of claw lesions than can be performed on living animals. This is especially important when using young animals with an overall low level of claw lesions. By slaughtering the gilts and collecting the claws, it was possible to score them more thoroughly in a laboratory environment than could be done in practice on live animals. Previous studies of claw lesions have often been performed on live pigs, either of varying age (Ehlorsson et al., 2002; Gjein and Larssen, 1995b; Olsson and Svendsen, 2002) or displaying a more limited age range (Díaz et al., 2013). Only a few studies on live animals have been complemented with studies on slaughtered gilts/sows, which were culled according to the normal routines in the herd and without systematic selection for a particular study (Gjein and Larssen, 1995b).

Claw lesions in live sows can be studied and scored on sows lying down in the farrowing room (Díaz et al., 2014), using equipment designed for claw trimming (Díaz et al., 2013; Olsson and Svendsen, 2002) or a mobile device for on-farm claw scoring (Van Riet et al., 2012). According to our experience (Olsson \& Svendsen, 2002), scientific claw studies under the conditions found in practice are challenging. Studies in the farrowing section are influenced by the sows being confined or not. In addition to this, claw lesion studies on live, fully grown pigs are laborious and very time-consuming. Another problem is that the results 
vary with the physical conditions on the farm, such as level of lighting, cleanliness of the claws, whether the animals are calm or stressed and active during the survey etc. Evaluating the severity of a lesion on a living animal is also complicated. For example, (KilBride et al., 2009a) reported that post mortem inspections of feet with lesions indicated that internal pathological changes could be more severe than what could be judged externally.

Assessing the feet of slaughtered pigs, as suggested in our model, provides the possibility to study claw lesions both externally and internally, to compare all the specimens and assess the claw lesions without time stress. Using this method, studies to investigate lesion depth are also possible. As in our study the claw capsule was gently removed at the laboratory and it could be demonstrated the cracks of the heel sole junction area was directly associated with sole hemorrhages and an ulceration of the corium. The centre of the ulceration corresponded to the posterior part of the claw bone and the process is exactly the same as in a bovine sole ulcer (Fig. 5; Ossent and Lischer, 1998). Blind testing, with the observer unaware of the treatment to which the individual gilt had been exposed, was another detail used in this study to obtain objective unbiased results.

When evaluating claw lesions, the scoring system used is an important issue. We used a slightly modified version of the lesion scoring system developed by Gjein and Larssen (1995c), which involves evaluation of six positions on the claw: cracks in the side wall, the white line or the toe; and lesions in the heel, in the junction between heel and toe and overgrown heel. The only modification used was a reduction from a five-point scale to a fourpoint scale, since no "very serious" (level 5) lesions were found in the young gilts used in the study. However, we recommend using the most up-to-date scoring system available at the time of the start of a study. 
Without a standardised scoring system for describing claw lesions, it is impossible to compare different studies with each other. Therefore, when studying claw lesions, it is recommended that researchers use a scoring system already developed and tested. However, even if the same scoring system is used, different observers may evaluate lesions slightly differently. Use of a scoring guide with descriptions and photos (for example the Feet First Lesions Scoring System; http://www.zinpro.com/lameness/swine/lesion-identification) is suggested to reduce such problems. For example, this approach has been used to test the repeatability and interrater agreement when assessing claw disease in cattle, with good results (Bergsten, 1993; Manske, 2002).

In our study, the claw lesion evaluations were made by the same observer, but on two different occasions (two batches). Since batch effect was significant for claw lesion score in the hard horn, the possibility of assessment bias could not be excluded. Therefore, an even better approach would have been to evaluate all the claws at the same time.

It was concluded that regrouping, in pigs kept on concrete flooring with a limited amount of straw caused both more numerous and more severe claw and body lesions compared to not regrouping. These results indicate that more focus on group management and how to decrease agonistic activity in animal groups is an important part of the work to reduce the frequency of claw problems in group housing.

The model proposed here would also be a successful experimental design for studying e.g. different flooring conditions (soft versus hard) and their role in development of claw lesions in pigs. Regrouping on concrete flooring would then act as a control to regrouping on soft flooring.

\section{ACKNOWLEDGEMENTS}


This work was supported by Partnership Alnarp and by the Swedish University of Agricultural Sciences. The able technical assistance of Mats Olsson at the research farm is much appreciated.

\section{REFERENCES}

Anil, S.S., Anil, L., Deen, J., 2009. Effect of lameness on sow longevity. J. Am. Vet. Med. Assoc. 235, 734-738.

Anil, S.S., Anil, L., Deen, J., Baidoo, S., Walker, R., 2007. Factors associated with claw lesions in gestating sows. J. Swine Heal. Prod. 15, 78-83.

Bench, C.J., Rioja-Lang, F.C., Hayne, S.M., Gonyou, H.W., 2013. Group gestation sow housing with individual feeding-II: How space allowance, group size and composition, and flooring affect sow welfare. Livest. Sci. 152, 218-227.

Bergsten, C., 1993. A photometric method for recording hoof diseases in cattle, with special reference to haemorrhages of the sole. Acta Vet. Scand. 34, 281-286.

Borderas, T.F., Pawluczuk, B., de Passille, A.M., Rushen, J., 2004. Claw Hardness of Dairy Cows: Relationship to Water Content and Claw Lesions. J. Dairy Sci. 87, 2085-2093.

Cador, C., Pol, F., Hamoniaux, M., Dorenlor, V., Eveno, E., Guyomarc'h, C., Rose, N., 2014. Risk factors associated with leg disorders of gestating sows in different group-housing systems: a cross-sectional study in 108 farrow-to-finish farms in France. Prev. Vet. Med. $116,102-10$.

Camerlink, I., Turner, S.P., Ursinus, W.W., Reimert, I., 2014. Aggression and Affiliation during Social Conflict in Pigs. PLoS One 9, 1-21.

De Koning, R., 1984. Injuries in confined sows. Incidence and relation with behaviour. Ann Rech Vet. 15, 205-214.

Díaz, J., Fahey, A., Boyle, L., 2014. Effects of gestation housing system and floor type during lactation on locomotory ability; body, limb, and claw lesions; and lying-down behavior of lactating sows. J Anim Sci 92, 1675-1685.

Díaz, J.A.C., Fahey, A.G., Kilbride, A.L., Green, L.E., Boyle, L.A., 2013. Longitudinal study of the effect of rubber slat mats on locomotory ability, body, limb and claw lesions, and dirtiness of group housed sows. J Anim Sci 91, 3940-3954.

Ehlorsson, C.J., Olsson, O., Lundeheim, N., 2002. Investigations of housing and environmental factors affecting the claw health in group housed dry sows. Sven. Veterinärtidning 54, 297-304. 
Engblom, L., Lundeheim, N., Strandberg, E., Schneider, M.D.P., Dalin, A.-M., Andersson, K., 2008. Factors affecting length of productive life in Swedish commercial sows. J. Anim. Sci. 86, 432-41.

Enokida, M., Sasaki, Y., Hoshino, Y., Saito, H., Koketsu, Y., 2011. Claw lesions in lactating sows on commercial farms were associated with postural behavior but not with suboptimal reproductive performance or culling risk. Livest. Sci. 136, 256-261.

EU, 2008. COUNCIL DIRECTIVE 2008/120/EC.

Gjein, H., Larssen, R.B., 1995a. The effect of claw lesions and claw infections on lameness in loose housing of pregnant sows. Acta Vet. Scand. 36, 451-459.

Gjein, H., Larssen, R.B., 1995b. Housing of pregnant sows in loose and confined systems - a field study 2. Claw lesions: Morphology, prevalence, location and relation to age. Acta Vet. Scand. 36, 433-442.

Gjein, H., Larssen, R.B., 1995c. Housing of pregnant sows in loose and confined systems--a field study 1. Vulva and body lesions, culling reasons and production results. Acta Vet Scand 36(2), 185-200.

Greenwood, E.C., Plush, K.J., van Wettere, W.H.E.J., Hughes, P.E., 2014. Hierarchy formation in newly mixed, group housed sows and management strategies aimed at reducing its impact. Appl. Anim. Behav. Sci. 160, 1-11.

Grégoire, J., Bergeron, R., D’Allaire, S., Meunier-Salaün, M.-C., Devillers, N., 2013. Assessment of lameness in sows using gait, footprints, postural behaviour and foot lesion analysis. Animal 7, 1163-73.

Heinonen, M., Peltoniemi, O., Valros, A., 2013. Impact of lameness and claw lesions in sows on welfare, health and production. Livest. Sci. 156, 2-9.

Jensen, T.B., Bonde, M.K., Kongsted, a G., Toft, N., Sørensen, J.T., 2010. The interrelationships between clinical signs and their effect on involuntary culling among pregnant sows in group-housing systems. Animal 4, 1922-1928.

Jorgensen, B., 2003. Influence of floor type and stocking density on leg weakness, osteochondrosis and claw disorders in slaughter pigs. Anim. Sci. 77, 439-449.

KilBride, A.L., Gillman, C.E., Green, L.E., 2010. A cross-sectional study of prevalence and risk factors for foot lesions and abnormal posture in lactating sows on commercial farms in England. Anim. Welf. 19, 473-480.

KilBride, A.L., Gillman, C.E., Ossent, P., Green, L.E., 2009a. A cross sectional study of prevalence, risk factors, population attributable fractions and pathology for foot and limb lesions in preweaning piglets on commercial farms in England. BMC Vet. Res. 5, 31.

Kilbride, A.M.Y., Gillman, C., Ossent, P., Green, L., 2009b. Impact of flooring on the health and welfare of pigs. In Pract. 31, 390-395. 
Kornegay, E. T.; Bryant, K. L.; Notter, D.R., 1990. Toe lesion development in gilts and sows housed in confinement as influenced by toe size and toe location. Appl. Agric. Res. 5, $327-334$.

Li, Y.Z., Gonyou, H.W., 2013. Comparison of management options for sows kept in pens with electronic feeding stations 445-453.

Manske, T., 2002. Hoof Lesions and Lameness in Swedish Dairy Cattle. Prevalence, risk factors, effects of claw trimming, and consequences for productivity. Doctoral thesis. Swedish University of Agricultural Sciences, Skara.

Minitab, 2011, 2011. Manual Minitab 16 [WWW Document]. URL http://www.4shared.com/document/tufGmcsz/Manual_minitab_16.htm

Mustonen, K., Ala-Kurikka, E., Orro, T., Peltoniemi, O., Raekallio, M., Vainio, O., Heinonen, M., 2011. Oral ketoprofen is effective in the treatment of non-infectious lameness in sows. Vet. J. 190, 55-59.

Nalon, E., Conte, S., Maes, D., Tuyttens, F.A.M., Devillers, N., 2013. Assessment of lameness and claw lesions in sows. Livest. Sci. 156, 10-23.

Olsson, A.-C., Andersson, M., Botermans, J., 2011. Animal interaction and response to electronic sow feeding (ESF) in 3 different herds and effects of function settings to increase capacity $137,268-272$.

Olsson, A.C., Svendsen, J., 2002. Claw health problems in gestating sows and the influence of flooring on the occurence of injuries. Swedish Univ. Agric. Sci. Dep. Biosyst. Technol. Report 128, 1-59.

Olsson, A.C., Svendsen, J., 2004. Different amounts of straw used for gestating sow housing, and effects on claw health, welfare and pen function. Swedish Univ. Agric. Sci. Dep. Biosyst. Technol. Report 131, 1-45.

Ossent, P., Lischer C.J. Bovine laminitis: the lesions and their pathogenesis. In Practice. 1998, 20, 415-27.

Pluym, L., Nuffel, A. Van, Dewulf, J., 2011. Prevalence and risk factors of claw lesions and lameness in pregnant sows in two types of group housing. Vet. Med. 56, 101-109.

Pluym, L., Van Nuffel, A., Maes, D., 2013. Treatment and prevention of lameness with special emphasis on claw disorders in group-housed sows. Livest. Sci. 156, 36-43.

Pluym, L.M., Maes, D., Vangeyte, J., Mertens, K., Baert, J., Van Weyenberg, S., Millet, S., Van Nuffel, A., 2013. Development of a system for automatic measurements of force and visual stance variables for objective lameness detection in sows: SowSIS. Biosyst. Eng. 116, 64-74.

SAS, 2009. SAS/STAT(R) 9.2 User's Guide, Second Edition [WWW Document]. URL http://support.sas.com/documentation/cdl/en/whatsnew/62580/HTML/default/viewer.htm \#titlepage.htm 
Stevens, B., Karlen, G.M., Morrison, R., Gonyou, H.W., Butler, K.L., Kerswell, K.J., Hemsworth, P.H., 2015. Effects of stage of gestation at mixing on aggression, injuries and stress in sows. Appl. Anim. Behav. Sci. 165, 40-46.

Stukenborg, A., Traulsen, I., Puppe, B., Presuhn, U., Krieter, J., 2011. Agonistic behaviour after mixing in pigs under commercial farm conditions. Appl. Anim. Behav. Sci. 129, $28-35$.

Svendsen, J., Andersson, M., Olsson, A., Rantzer, D., Lundqvist, P., 1990. Group housing of sows in gestation in insulated and uninsulated buildings. Results of a questionnaire survey, farm visits and grouping studies. Swedish Univ. Agric. Sci. Dep. Farm Buidings, Rep. 66.

Van Amstel, S., Doherty, T., 2010. Claw horn growth and wear rates, toe length, and claw size in commercial pigs: A pilot study 18, 239-243.

Van Riet, M.M.., Vangeyte, J., Nalon, E., Tuyttens, F.A.M., Janssens, G.P.J., Maes, D., Millet, S., 2012. A novel mobile device for on-farming claw scoring in sows. CIGR AgEng Agric. Eng. a Heal. Life, Val. Spain, 8-12 July 2012. C-0940.

Vestergaard, K.A.J., Wachmann, H., Verner, O.G., 2005. Klovpleje hos losgående draegtige soer. Videncenter Svineproduktion, Medd. Nr 687 1-23.

Willgert, K.J.E., Brewster, V., Wright, A.J., Nevel, A., 2014. Risk factors of lameness in sows in England. Prev. Vet. Med. 113, 268-272.

Wolf, F., 2011. Evaluierung der Überlängen von Haupt- und Afterklauen in Ferkelerzeugerbetrieben unter Verwendung des Klauenpflegestandes (PPES) und des EDV-Klauenmanagers. Vet. Med. Univ. Wien, Diplomarbeit, 1-46. 
Table 1. Regrouping schedule used in treatment RR for individual gilts

\begin{tabular}{llll}
\hline & Pen A & Pen B & Pen C \\
\hline Original groups & A1, A2, A3 & B1, B2, B3 & C1, C2, C3 \\
Regrouping No. 1 (8 months) & $\mathbf{A 1 , ~ B 1 , ~ C 1 ~}$ & A2, B2, C2 & A3, B3, C3 \\
Original groups & A1, A2, A3 & B1, B2, B3 & C1, C2, C3 \\
Regrouping No. 2 (9 months) & $\mathbf{A 1 , ~ B 2 , ~ C 3 ~}$ & $\mathbf{A 2 , ~ B 3 , ~ C 1 ~}$ & $\mathbf{A 3 , ~ B 1 , ~ C 2 ~}$ \\
Original groups & A1, A2, A3 & B1, B2, B3 & C1, C2, C3 \\
Regrouping No. 3 (10 months) & A1, B3, C2 & A2, B1, C3 & A3, B2, C1 \\
Original groups & A1, A2, A3 & B1, B2, B3 & C1, C2, C3 \\
\hline
\end{tabular}


Table 2. Claw lesion scores, soft horn lesion scores, hard horn lesion scores and body lesion scores of gilts with no regrouping (NR) and gilts with repeated regrouping (RR). The calculations are per pen (mean \pm s.d)

\begin{tabular}{llll}
\hline & $\begin{array}{l}\text { No regrouping } \\
(\mathrm{NR})\end{array}$ & $\begin{array}{l}\text { Repeated } \\
\text { regrouping (RR) }\end{array}$ & p-value \\
\hline $\begin{array}{lll}\text { No. of pens } \\
\text { No. of gilts }\end{array}$ & 12 & 12 & \\
& 36 & 36 & $<0.001$ \\
Body lesion scores & $0.46 \pm 0.29$ & $1.71 \pm 0.38$ & \\
& & & 0.004 \\
Claw lesion scores & $0.23 \pm 0.13$ & $0.40 \pm 0.13$ & 0.014 \\
-soft horn lesion scores & & & \\
-hard horn lesion scores & & & \\
& $0.14 \pm 0.09$ & $0.23 \pm 0.09$ & 0.005 \\
\hline
\end{tabular}

${ }^{1)}$ Soft horn lesions = heel+overgrown heel+transition heel/toe.

${ }^{2)}$ Hard horn lesions = wall cracks+white line+toe. 


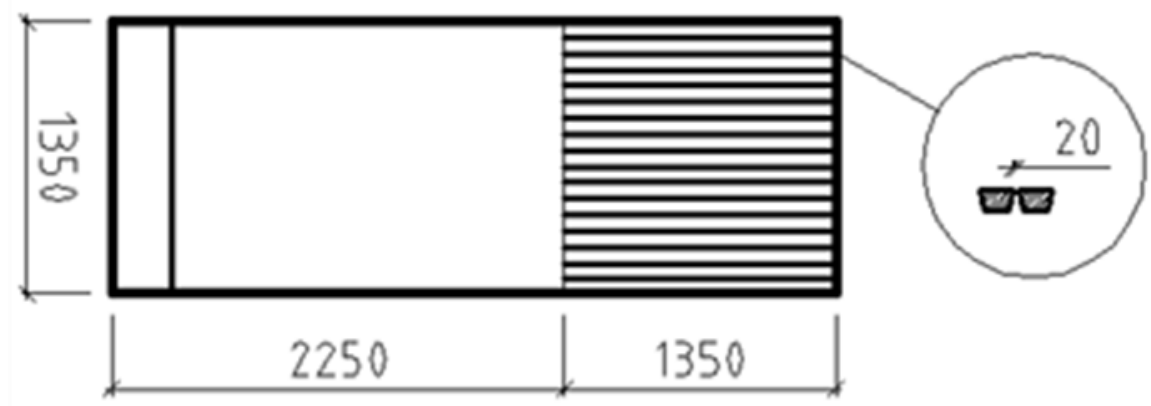

Fig. 1. Experimental pen with solid concrete feeding and resting area and slatted dunging area (concrete slats with $20 \mathrm{~mm}$ slot width and $80 \mathrm{~mm}$ beam width). Water nipples were placed over the feeding trough and dunging area. 


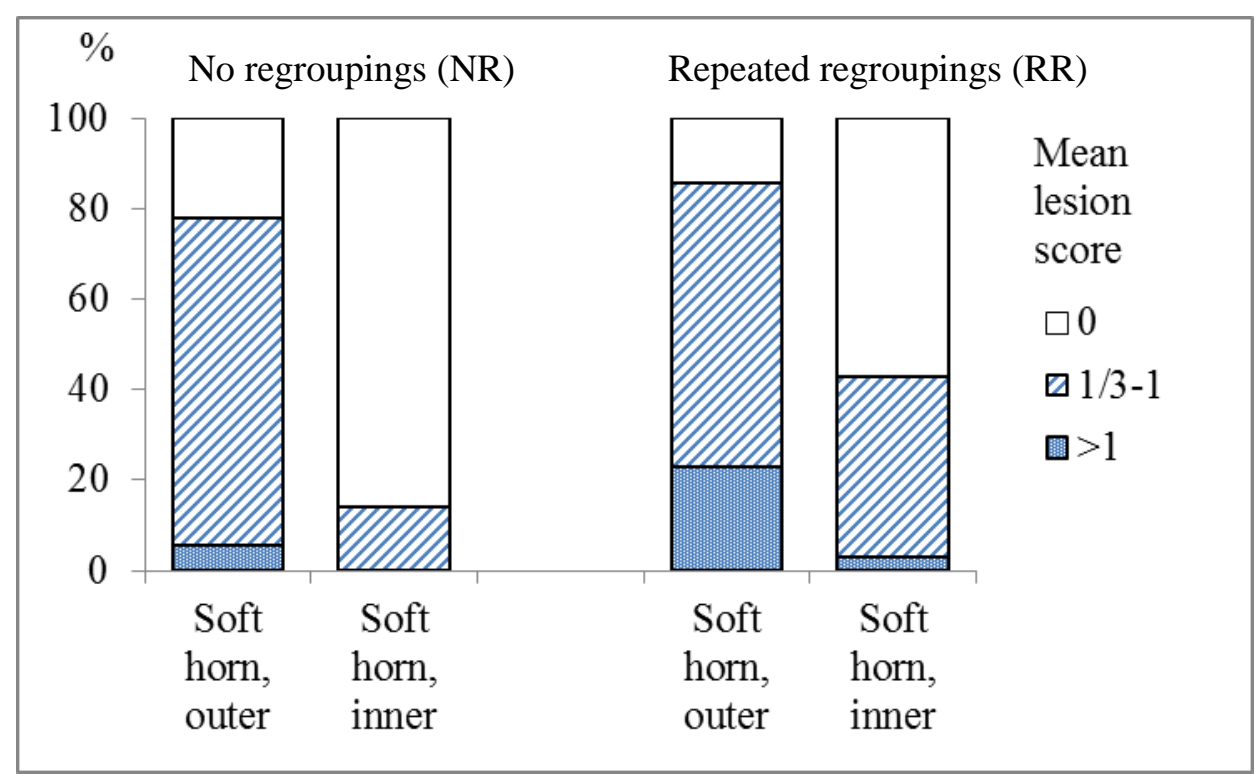

Fig. 2. Proportion of gilts with different claw lesion scores (1/3-1 or $>1)$ and without lesions (mean lesion score $=0$ ) on the soft horn (heel, over-grown heel and transition heel/toe) of the outer and inner digits in the treatments with no regrouping (NR) and repeated regrouping (RR). 


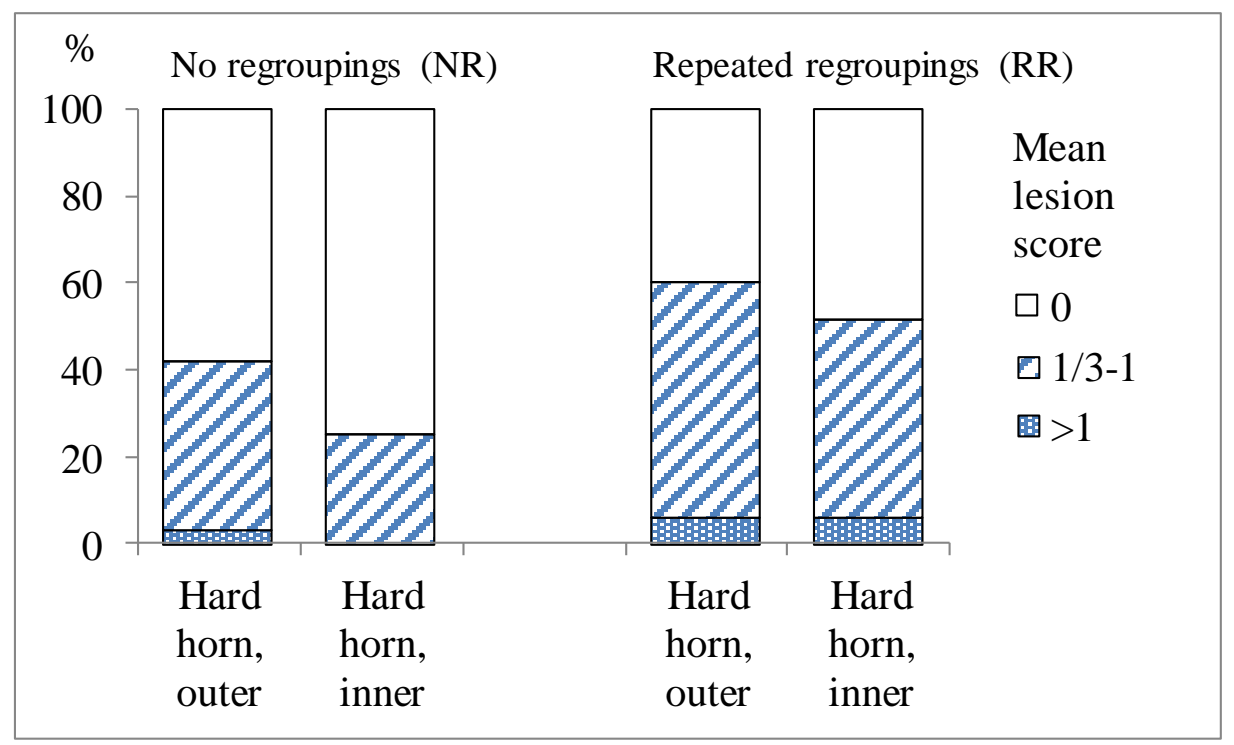

Fig. 3. Proportion of gilts with different claw lesion scores $(1 / 3-1$ or $>1)$ and without lesions (mean lesion score $=0$ ) on the hard horn (wall, white line and toe) of the outer and inner digits in the treatments with no regrouping (NR) and repeated regrouping (RR). 


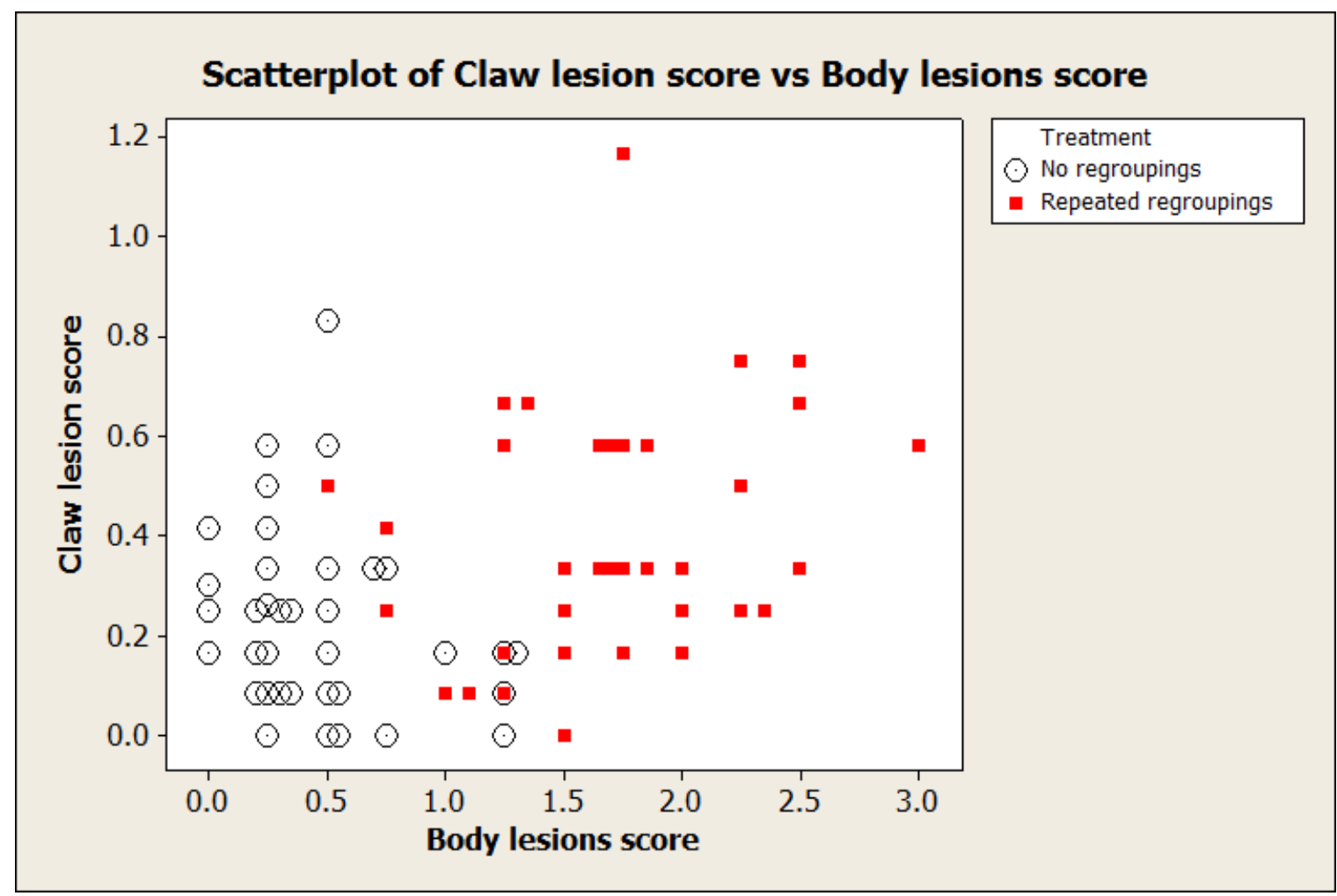

Fig. 4. Scatterplot illustrating the relationship between claw lesion score and body lesion score per gilt for all gilts $(n=72)$. Correlation coefficient $=0.36(p=0.002)$. 

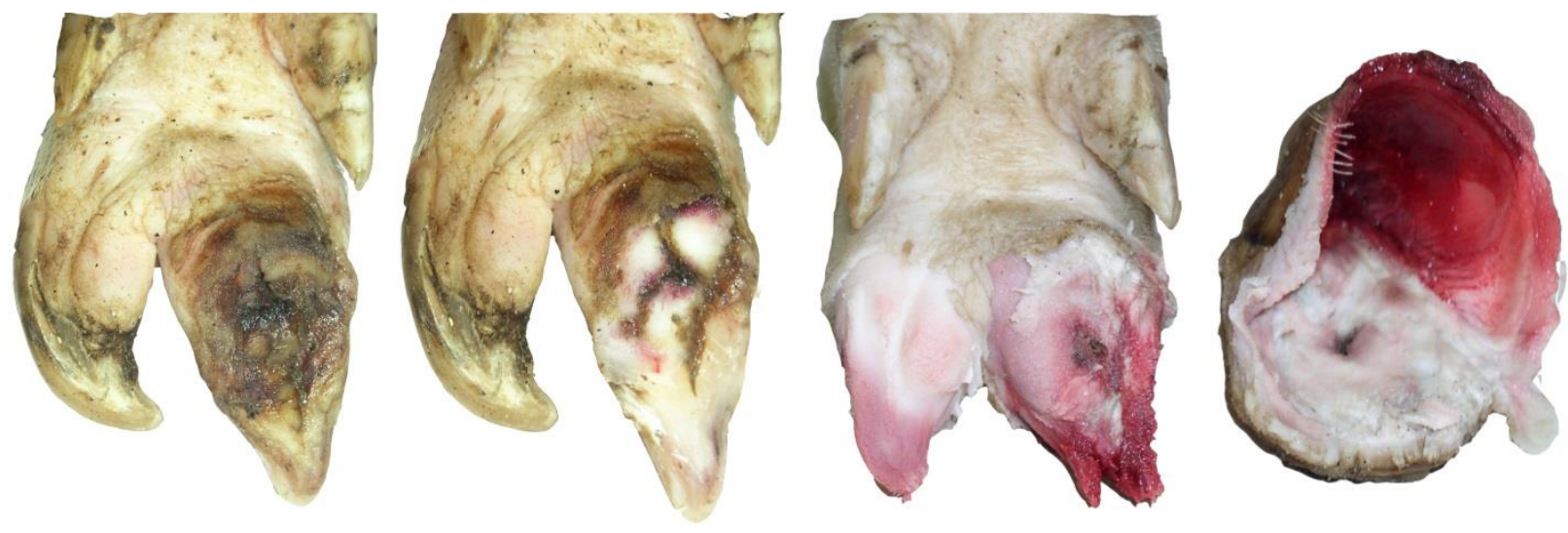

Fig 5. Right rear claw from a gilt regrouped on concrete flooring. The lesion was scored 3, deep cracks which revealed sole haemorrhages after paring off a thin slice of claw horn and a corium ulceration as the cause of the lesions of the claw horn. 